\title{
MENGAPA GENERASI MUDA ENGGAN BEKERJA DI SEKTOR PERTANIAN? MODEL PERSAMAAN STRUKTURAL SEKTOR PERTANIAN DI KABUPATEN JEMBRANA
}

\author{
Adi Putrayasa $^{1 \S}$, I Komang Gde Sukarsa ${ }^{2}$, Eka N. Kencana ${ }^{3 \S}$ \\ ${ }^{1}$ Program Studi Matematika, Fakultas MIPA - Universitas Udayana [Email: m.a.putra.y@gmail.com] \\ ${ }^{2}$ Program Studi Matematika, Fakultas MIPA - Universitas Udayana [Email: gedesukarsa@unud.ac.id] \\ ${ }^{3}$ Program Studi Matematika, Fakultas MIPA - Universitas Udayana [Email: i.putu.enk@unud.ac.id] \\ ${ }^{\S}$ Corresponding Author
}

\begin{abstract}
Agriculture in Bali has profound importance, namely as a natural tourist attraction and is one of the sectors with the most workers absorb as well the largest contributor to regional income for Bali Province. Currently, the agriculture sector in Bali is experiencing the problem of decreasing the workforce due to the reluctance of future generations to continue farming inherited from their families. The purpose of this paper is to identify the factors causing the reluctance of future generations to continue family farming and to study the causality of these factors to the reluctance for continuing family farming. This study uses a variance-based structural equation modeling (PLSSEM). Internal and external motivation to continue family farming as well the perception of agricultural works are the exogenous variables, and the reluctance to continue family farming is the endogenous variable on the model. The data in this study obtained from interviewing 115 respondents in the Jembrana Regency of Bali. The study's result justifies that internal factors, external factors, and perceptions of agricultural work influenced the reluctance to continue family farming.
\end{abstract}

Keywords: agriculture sector, family farming, PLS-SEM.

\section{PENDAHULUAN}

BPS atau Badan Pusat Statistik Indonesia (2020) memperhitungkan penduduk Indonesia pada tahun 2019 sejumlah 268,10 juta jiwa dengan laju pertumbuhan penduduk per tahun sebesar 1,15 persen. Total penduduk Indonesia pada tahun 2019 yang berusia 15 tahun ke atas mencapai 197,91 juta jiwa dengan penduduk pada kelompok usia ini terkategorikan angkatan kerja dan bukan angkatan kerja masing-masing sejumlah 133,56 juta dan 64,35 juta jiwa, sehingga persentase angkatan kerja terhadap jumlah penduduk mencapai $\approx 49.82$ persen.

Indonesia menduduki peringkat keempat dalam hal jumlah penduduk setelah Cina, India, dan Amerika Serikat. Sebagai salah satu modal dasar pembangunan, selain sebagai pasar produk dan/atau jasa yang dihasilkan industri, penduduk pada usia kerja juga merupakan faktor penting pada kegiatan produksi yang berlangsung.

Menurut catatan Kementerian Pemberdayaan Perempuan dan Perlindungan Anak (PPPA)
(2018), lapangan-lapangan usaha pertanian, perdagangan, dan industri pengolahan merupakan tiga besar penyerapan angkatan kerja Indonesia. Pada angkatan kerja yang berada dalam kelompok umur 15-37 tahun (pada laporan yang diacu disebut generasi milenial), persentase generasi milenial pada lapangan usaha pertanian, kehutanan, dan perikanan menurun dari 25,78 persen pada tahun 2015 menjadi 21,95 persen pada tahun 2017. Sebaliknya generasi milenial yang bekerja di sektor industri pengolahan serta perdagangan besar dan eceran; reparasi mobil dan motor masing-masing meningkat dari 17,06 persen dan 19,79 persen pada tahun 2015 menjadi 17,43 persen dan 20,02 persen pada tahun 2017. Sebagai salah satu negara agraris di Asia Tenggara, fakta empiris ini merupakan satu indikasi awal sektor pertanian di Indonesia mulai kehilangan daya tariknya bagi generasi milenial yang dapat bermuara pada terancamnya keberlanjutan lapangan usaha pertanian, kehutanan, dan perikanan. 
Kabupaten Jembrana yang berlokasi di ujung barat Pulau Bali, tercatat memiliki luas wilayah $841,80 \mathrm{~km}^{2}(\approx 14,93$ persen luas Bali) dan menduduki posisi ketiga setelah Kabupaten Buleleng dan Kabupaten Tabanan dari luas wilayah 9 kabupaten/kota di Provinsi Bali. Tercatat memiliki indeks pembangunan manusia (IPM) sebesar 72,35; lebih kecil dari rataan IPM Bali 75,38; Jembrana yang terdiri dari lima kecamatan, pada tahun 2019 berpenduduk 217.000 jiwa dengan persentase penduduk miskin 4,88 persen, lebih besar bila dibandingkan persentase penduduk miskin di Provinsi Bali sebesar 3,79 persen (BPS Kabupaten Jembrana, 2020; BPS Provinsi Bali, 2020).

Struktur perekonomian Kabupaten Jembrana hingga saat ini masih didominasi sektor primer. Pada tahun 2019 produk domestik regional bruto (PDRB) atas dasar harga berlaku (adhb) Kabupaten Jembrana sebesar Rp 14.162,33 milyar dengan persentase kontribusi lapangan usaha pertanian, kehutanan, dan perikanan sebesar 20,43 persen (BPS Kabupaten Jembrana, 2020). Meski demikian, tenaga kerja di sektor ini menurun 7,60 persen dalam kurun waktu dua tahun, dari 43.014 jiwa pada tahun 2017 menjadi 39.745 jiwa pada tahun 2019.

Penurunan jumlah tenaga kerja sektor pertanian di Kabupaten Jembrana pada periode 2017-2019 yang melebihi penurunan pada level provinsi sebesar 1,69 persen - jumlah tenaga kerja di sektor pertanian di Bali tercatat 466.307 jiwa pada tahun 2017 dan 458.430 jiwa pada tahun 2019 (BPS Provinsi Bali, 2020), merupakan ancaman serius terhadap kedaulatan pangan. Menurut Kementerian PPPA (2018, hal. 90), menurunnya minat generasi milenial bekerja pada sektor pertanian tidak terlepas dari (a) ketertarikannya untuk menggeluti usaha yang tidak monoton; (b) niat untuk bebas dalam mengembangkan usaha; dan (c) berusaha pada lapangan usaha yang memberikan keuntungan maksimal.

Mencermati fakta empiris tentang menurunnya jumlah tenaga kerja di sektor pertanian serta dampaknya kepada kedaulatan pangan daerah, tulisan ini bertujuan mengelaborasi determinan keengganan generasi muda meneruskan usaha tani keluarga di Kabupaten Jembrana serta memeriksa kausalitas faktor internal dan eksternal generasi muda dengan persepsi generasi muda tentang pekerjaan petani sebagai determinan dari keengganan generasi muda meneruskan usaha tani keluarga. Sebuah model persamaan struktural (structural equation modeling/SEM) dibangun untuk mengkaji kausalitas ini dan SmartPLS dari Ringle et al. (2015) digunakan untuk menganalisis data.

\section{METODE PENELITIAN}

Studi tentang keengganan generasi muda di Kabupaten Jembrana meneruskan usaha tani keluarga dilakukan menggunakan pendekatan kuantitatif. Menggunakan teknik pengambilan sampel secara proporsional, 115 responden yang keluarganya menjadi anggota subak sawah di lima kecamatan di Kabupaten Jembrana dipilih. Tabel 1 menunjukkan sampling frame dan jumlah sampel di masing-masing kecamatan:

Tabel 1. Sampling Frame dan Sampel di lima Kecamatan

\begin{tabular}{l|c|c|c|c}
\hline Kecamatan & $\begin{array}{c}\text { Subak } \\
\text { Sawah }\end{array}$ & Anggota & $\begin{array}{c}\text { Proporsi } \\
\text { (persen) }\end{array}$ & Sampel \\
\hline Melaya & 20 & 1.846 & 16 & 19 \\
\hline Negara & 22 & 2.995 & 27 & 31 \\
\hline Jembrana & 16 & 1.811 & 16 & 18 \\
\hline Mendoyo & 15 & 3.858 & 34 & 39 \\
\hline Pekutatan & 8 & 757 & 7 & 8 \\
\hline Jembrana & 81 & 11.267 & 100 & 115 \\
\hline
\end{tabular}

Sumber: Hasil Analisis, 2020

Studi ini menggunakan data primer yang dikumpulkan dengan mendistribusikan kuesioner kepada 115 responden terpilih. Kuesioner disusun dengan item-item berskala Likert berderajat lima. Sebelum didistribusikan, kuesioner diperiksa validitas dan reliabilitasnya pada tahap prariset dengan menyebarkannya kepada 40 generasi milenial keluarga petani di Kecamatan Negara dan Kecamatan Mendoyo. Item pernyataan yang terbukti tidak valid pada tahap prariset dieliminasi pada tahap pengumpulan data primer.

Menurut Ryan \& Deci (2000a) motivasi merupakan kajian penting pada ranah psikologi. Motivasi dimaknai sebagai 'segala hal yang mendorong seseorang melakukan sesuatu'. Seseorang akan memperoleh hasil optimal dari aktivitas yang dilakukannya bila termotivasi, sebaliknya hasil kegiatan dari orang yang tidak/kurang termotivasi cenderung tidak akan optimal. Kedua penulis selanjutnya menuangkan pemikirannya tentang motivasi dalam sebuah teori yang disebutnya the selfdetermination theory (SDT) (Ryan \& Deci, 2000b). 
Terkait dengan keengganan generasi muda melanjutkan usaha tani keluarganya, menggunakan teori SDT yang mengklasifikasikan motivasi menjadi dua tipe motivasi internal dan motivasi eksternal, maka pada model persamaan struktural yang dirancang kedua tipe motivasi generasi muda dalam memilih jenis pekerjaan diposisikan sebagai dua laten eksogen yang dihipotesiskan berpengaruh terhadap persepsi generasi muda tentang bekerja di sektor pertanian dan keengganan generasi muda untuk melanjutkan usaha tani keluarga.

Khusus untuk laten motivasi eksternal, riset ini menghipotesiskan sebagai laten berorde dua, yang terefleksi pada dua laten orde satu yaitu status sosial ekonomi keluarga dan faktor dukungan keluarga bagi anak dalam memilih pekerjaan. Secara spesifik model yang dibangun merupakan model persamaan struktural berhirarki yang teknik analisisnya diperkenalkan oleh Wetzels et al. (2016). Model konseptual dari studi ini diperlihatkan pada Gambar 1 .

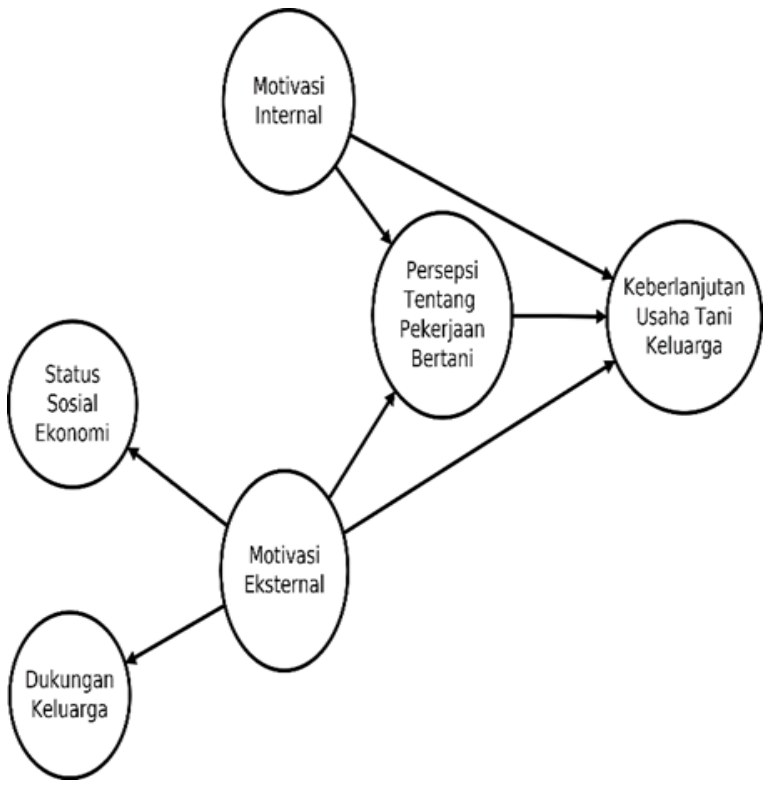

Gambar 1. Model Konseptual Riset

\section{HASIL DAN PEMBAHASAN}

\subsection{Uji Instrumen Penelitian}

Pada tahap prariset yang ditujukan memeriksa validitas item dan reliabilitas variabel laten pada model, terdapat sebuah item pada laten motivasi internal yang tidak valid. Validitas item wajib diperiksa bila item merupakan indikator reflektif dari sebuah variabel laten (Hair et al., 2017). Sebuah item reflektif dinyatakan valid bila nilai korelasinya dengan item-item lain pada laten yang sama setidak-tidaknya bernilai sama dengan nilai ukuran koefisien korelasi yaitu $0,30 \quad(\rho \geq 0,30)$ (Churchill, 1979). Saat nilai $\rho<0,30$ disarankan untuk mengeliminasinya sebagai salah satu indikator reflektif dari laten. Sementara itu reliabilitas laten diukur dari nilai koefisien Cronbach. Sebuah variabel laten dianggap reliabel bila koefisien $\alpha \geq 0,60$ (Bollen, 2002; Hair et al., 2019). Hasil uji validitas dan reliabilitas ditunjukkan pada Tabel 2.

Tabel 2. Uji Validitas dan Reliabilitas

\begin{tabular}{|c|c|c|c|}
\hline Kode & Item Pernyataan (Diringkas) & $\rho$ & $\alpha^{*}$ \\
\hline \multicolumn{4}{|c|}{ Motivasi Internal (INT) Nilai $\alpha=\mathbf{0 , 5 8 7}$} \\
\hline $\mathrm{INT}_{1}$ & Gender tidak cocok sebagai petani & 0,164 & 0,791 \\
\hline $\mathrm{INT}_{2}$ & Keahlian di bidang non-pertanian & 0,560 & 0,226 \\
\hline $\mathrm{INT}_{3}$ & Pengalaman di bidang non-pertanian & 0,513 & 0,293 \\
\hline \multicolumn{4}{|c|}{ Motivasi Eksternal (EXT) Nilai $\alpha=\mathbf{0 , 8 4 9}$} \\
\hline $\mathrm{FAM}_{1}$ & Orangtua jarang mengajak bertani & 0,535 & 0,839 \\
\hline $\mathrm{FAM}_{2}$ & Keahlian bertani orangtua memadai & &, 832 \\
\hline $\mathrm{FAM}_{3}$ & Orangtua membebaskan pilihan kerja & 0,781 & 0,834 \\
\hline $\mathrm{SES}_{1}$ & an pertanian keluarga terbatas & 0,423 & 0,853 \\
\hline $\mathrm{SES}_{2}$ & Hasil tidak mencukupi keperluan RT & 0,766 &, 803 \\
\hline$\overline{\mathrm{SES}_{3}}$ & Tingkat pendidikan orangtua rendah & 0,571 & 0,834 \\
\hline$\overline{\mathrm{SES}_{4}}$ & Pendapatan usaha tani kecil & 0,604 & 0,830 \\
\hline \multicolumn{4}{|c|}{ Dukungan Keluarga (FAM) Nilai $\alpha=\mathbf{0 , 7 1 9}$} \\
\hline \multicolumn{4}{|c|}{$\mathrm{FAM}_{1}$ Orangtua jarang mengajak bertani 0,527} \\
\hline \multicolumn{4}{|c|}{ FAM $_{2}$ Keahlian bertani orangtua memadai $\quad 0,500 \quad 0,683$} \\
\hline \multicolumn{4}{|c|}{$\mathrm{FAM}_{3}$ Orangtua membebaskan pilihan kerja $0,6280,516$} \\
\hline \multicolumn{4}{|c|}{ Sosial Ekonomi Keluarga (SES) Nilai $\alpha=\mathbf{0 , 7 3 3}$} \\
\hline $\mathrm{SES}_{1}$ & Lahan pertanian keluarga terbatas & 0,413 & 0,731 \\
\hline $\mathrm{SES}_{2}$ & Hasil tidak mencukupi keperluan RT & 0,696 & 0,559 \\
\hline$\overline{\mathrm{SES}_{3}}$ & Tingkat pendidikan orangtua rendah & 0,560 & 0,659 \\
\hline $\mathrm{SES}_{4}$ & Pendapatan usaha tani kecil & 0,458 & 0,716 \\
\hline \multicolumn{4}{|c|}{ Persepsi sebagai Petani (PER) Nilai $\alpha=\mathbf{0 , 7 0 0}$} \\
\hline $\mathrm{PER}_{1}$ & Bertani cocok dilakukan orangtua & 0,618 & 0,476 \\
\hline$\overline{\mathrm{PER}_{2}}$ & Pekerjaan bertani melelahkan & 0,585 & 0,515 \\
\hline $\mathrm{PER}_{3}$ & Petani dengan pendidikan rendah & 0,364 & 0,781 \\
\hline \multicolumn{4}{|c|}{$\begin{array}{l}\text { Keberlanjutan Pertanian (AVO) } \square \text { Nilai c } \\
\mathbf{0 , 9 0 3}\end{array}$} \\
\hline $\mathrm{AVO}_{1}$ & Pendidikan tidak di bidang pertanian & 0,803 & 0,882 \\
\hline $\mathrm{AVU}_{2}$ & ya hidup & 0,606 & 0,898 \\
\hline $\mathrm{AVO}_{3}$ & Hasil bertani tergantung musim & 0,768 & 0,886 \\
\hline $\mathrm{AVO}_{4}$ & Non-pertanian lebih menjanjikan & 0,715 & 0,890 \\
\hline $\mathrm{AVO}_{5}$ & Bertani untuk menambah income & 0,481 & 0,906 \\
\hline $\mathrm{AVO}_{6}$ & Lokasi rumah jauh dari lahan milik & 0,638 & 0,895 \\
\hline $\mathrm{AVO}_{7}$ & Tidak siap mengandalkan usaha tani & 0,747 & 0,887 \\
\hline $\mathrm{AVO}_{8}$ & Hak mengelola lahan belum ada & 0,602 & 0,898 \\
\hline $\mathrm{AVO}_{9}$ & Bertani bukan pilihan prioritas & 0,713 & 0,890 \\
\hline
\end{tabular}

*: Nilai $\alpha$ bila item dieliminasi

Sumber: Hasil Analisis, 2020

Hasil analisis pada Tabel 2 memperlihatkan terdapat sebuah item, $\mathrm{INT}_{1}$ yang memiliki nilai validitas kurang dari 0,30 sehingga perlu 
dieliminasi dari indikator reflektif motivasi internal. Memerhatikan hal ini, maka $\mathrm{INT}_{1}$ dieliminasi sehingga reliabilitas laten meningkat dari 0,587 menjadi 0,791 dan berada pada kriteria reliabel. Kelima variabel laten lainnya terbukti reliabel dan seluruh indikator yang digunakan valid. Mencermati hal ini, kuesioner dengan $\mathrm{INT}_{1}$ dieliminasi telah layak digunakan untuk mengumpulkan pendapat responden.

\subsection{Profil Responden}

Generasi milenial yang terpilih sebagai responden riset dominan berjenis kelamin lakilaki ( $\approx 64,4$ persen). Pada karakteristik umur dan tingkat pendidikan, sebagian besar responden berada pada kelompok umur 15-30 tahun $(\approx 92,2$ persen) dan tingkat pendidikan tertinggi yang diselesaikan ada pada jenjang SMA hingga pascasarjana, sejumlah 98,3 persen. Responden yang berpendidikan SMP hanya dua orang, dan tidak ada responden yang hanya berpendidikan SD ataupun tidak bersekolah.
Dilihat dari jenis pekerjaan responden, 74 dari 115 responden $(\approx 64,3$ persen) merupakan responden yang telah bekerja dengan jenis pekerjaan sebagai karyawan swasta menduduki peringkat pertama ( $\approx 50,0$ persen), disusul pada peringkat kedua bekerja sebagai wirausahawan $(\approx 18,9$ persen $)$. Memerhatikan responden dominan berpendidikan SMA ke atas, berada pada kelompok umur 15-30 tahun, dan berusaha atau bekerja di sektor swasta; maka penilaian responden mengenai enam variabel laten tentang keengganan generasi muda Kabupaten Jembrana berkiprah sektor pertanian bisa dipercaya.

\subsection{Model Persamaan Struktural}

Menggunakan SmartPLS sebagai alat analisis, model persamaan struktural yang dikembangkan serta hipotesis riset diperlihatkan pada gambar 2:

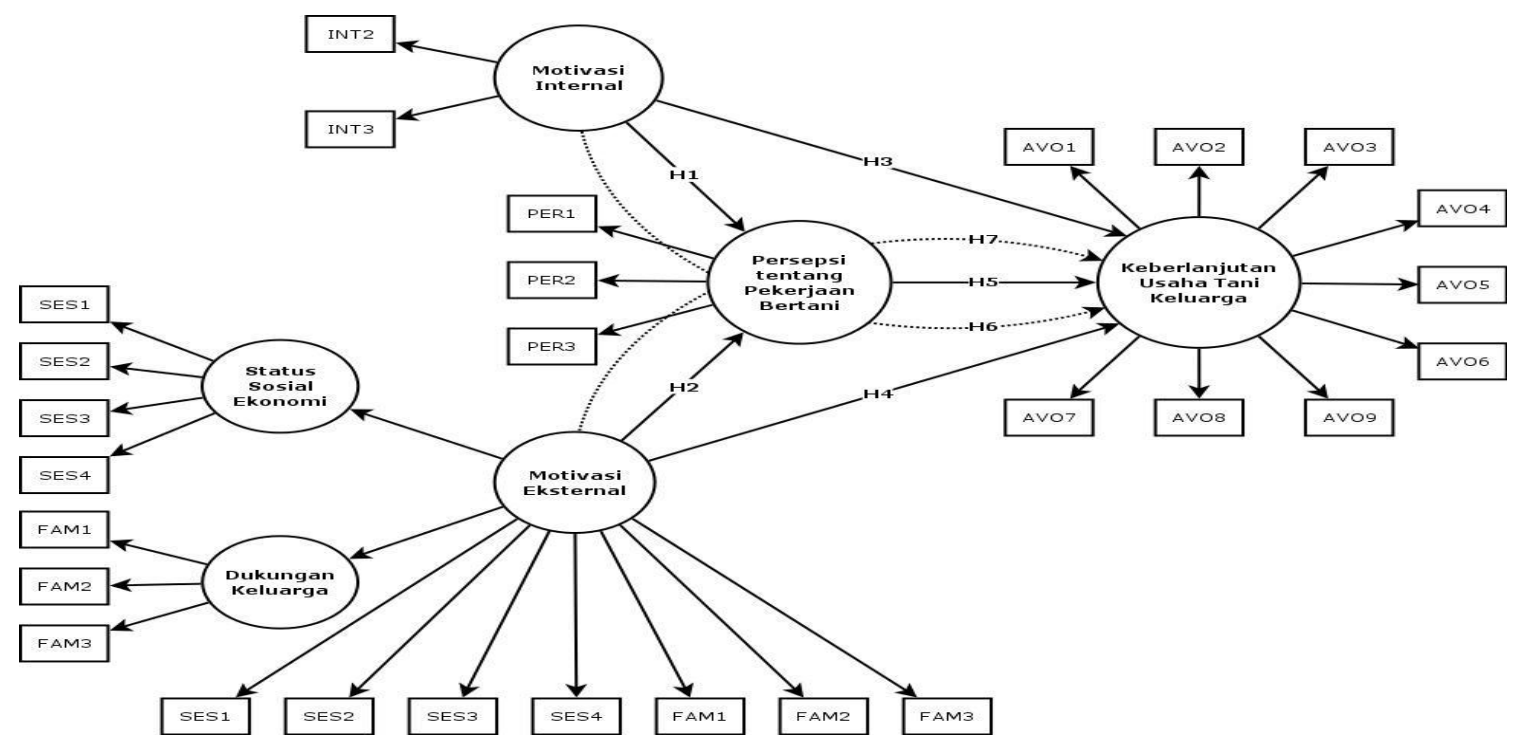

Gambar 2. Model Operasional dan Hipotesis Penelitian

Kausalitas antara laten-laten eksogen dengan laten endogen terkait dengan determinan keengganan generasi muda di Kabupaten Jembrana meneruskan usaha pertanian keluarga dinyatakan dalam 7 hipotesis berikut:

H1: Motivasi internal memengaruhi persepsi tentang bekerja sebagai petani;

H2: Motivasi eksternal memengaruhi persepsi tentang bekerja sebagai petani;

H3: Motivasi internal memengaruhi keberlanjutan usaha tani keluarga;
H4: Motivasi eksternal memengaruhi keberlanjutan usaha tani keluarga;

H5: Persepsi tentang bertani memengaruhi keberlanjutan usaha tani keluarga;

H6: Persepsi tentang bertani memediasi pengaruh motivasi internal pada keberlanjutan usaha tani keluarga; dan

H7: Persepsi tentang bertani memediasi pengaruh motivasi eksternal pada keberlanjutan usaha tani keluarga. 
Model persamaan struktural pada Gambar 2 sesungguhnya tersusun dari dua submodel yaitu (a) Model Pengukuran, dan (b) Model Struktural. Menurut Bollen (2002) dan Hair et al. (2017), submodel pengukuran menunjukkan kausalitas antara sebuah variabel laten dengan indikator-indikatornya dan submodel struktural merepresentasikan kausalitas antarlaten. Jika pada model pengukuran variabel laten $\xi_{j} ; j=$ $1, \ldots, q$ dengan $q$ menyatakan jumlah variabel laten pada model, masing-masing direfleksikan pada $p_{j}$ indikatornya; formulasi untuk indikator reflektif $x_{i}$ bisa dinyatakan dalam persamaan (1) dengan $p_{j}$ menyatakan jumlah indikator dari variabel laten ke-j, $\gamma_{0 j}$ dan $\epsilon_{i}$ masing-masing menyatakan nilai rataan dan galat (error) dari $x_{i}$ :

$$
x_{i}=\gamma_{0 j}+\gamma_{1 j} \xi_{j}+\epsilon_{i} ; i=1, \ldots, p_{j} .
$$

Pada model struktural, bila $\xi$ dan $\eta$ masingmasing menyatakan variabel laten eksogen dan endogen, maka kausalitas linear dari $\eta_{q}$ sebagai fungsi dari $\xi_{1}, \ldots, \xi_{k}$ dapat diekspresikan sebagai:

$$
\eta_{q}=\gamma_{0}+\gamma_{1} \xi_{1}+\cdots+\gamma_{i} \xi_{i}+\zeta_{q}
$$

dengan $\gamma_{0}$ dan $\zeta_{q}$ masing-masing menyatakan nilai rataan dan galat dari variabel laten (endogen) $\eta_{q}$.

\subsubsection{Analisis Model Pengukuran}

Untuk memahami kausalitas antarlaten dan memeriksa hipotesis pada model struktural, analisis harus diawali dengan memeriksa model pengukuran masing-masing laten. Hasil analisis dari model pengukuran diringkas pada Tabel 3 .

Pada Tabel 3, terdapat sejumlah indikator dengan nilai loading $<0,70$. Menurut Hair et al. (2017, p. 104), bila terdapat indikator dengan nilai loading $(l)$ ada pada rentang $0,40<l<$ 0,70 , sebaiknya keberadaan indikator diperiksa pada perubahan nilai average variance extracted (AVE) dan composite reliability (CR). Saat indikator dieliminasi sebagai indikator reflektif mampu menyebabkan AVE dan CR melebihi ambang bawah yang dipersyaratkan (AVE dan $\mathrm{CR} \geq 0,50)$ maka sepatutnya indikator dieliminasi; bila tidak, bisa dipertahankan.

\begin{tabular}{|c|c|c|c|c|}
\hline $\begin{array}{l}\text { Hubungan } \\
\text { Kausal }\end{array}$ & Loading & $\begin{array}{r}\text { Simp. } \\
\text { Baku }\end{array}$ & $\begin{array}{r}\text { Critical } \\
\text { Ratio }\end{array}$ & $p$ Value \\
\hline $\mathrm{INT}_{2} \leftarrow$ INT & 0,948 & 0,011 & 85,799 & 0,000 \\
\hline$\leftarrow$ INT & 880 & 0,044 & 19,849 & 0,000 \\
\hline $\mathrm{FAM}_{1} \leftarrow$ FAM & 809 & 0,053 & 15,298 & $\overline{0,000}$ \\
\hline $\mathrm{FAM}_{2} \leftarrow$ FAM & 708 & 0,077 & 9,254 & 0,000 \\
\hline $\mathrm{FAM}_{3} \leftarrow$ FAM & 803 & 0,052 & 15,470 & 0,000 \\
\hline $\mathrm{SES}_{1} \leftarrow \mathrm{SES}$ & 689 & 0,095 & 7,262 & $\overline{0,000}$ \\
\hline $\mathrm{SES}_{2} \leftarrow \mathrm{SES}$ & 833 & 0,035 & 23,867 &, 000 \\
\hline$\leftarrow$ SES & & 0,046 & 17,520 &, 000 \\
\hline $\mathrm{SES}_{4} \leftarrow \mathrm{SES}$ & 704 & 0,070 & 10,072 & 0,000 \\
\hline $\mathrm{FAM}_{1} \leftarrow$ EXT & & 0,070 & 9,603 & $\overline{, 000}$ \\
\hline $\mathrm{FAM}_{2} \leftarrow$ EXT & 642 & 0,083 & 7,726 & 0,000 \\
\hline $\mathrm{FAM}_{3} \leftarrow$ EXT & 764 & 0,067 & 11,378 &, 000 \\
\hline $\mathrm{SES}_{1} \leftarrow$ EXT & 578 & 0,108 & 5,377 & $\overline{0,000}$ \\
\hline $\mathrm{SES}_{2} \leftarrow$ EXT & 792 & 0,053 & 15,028 &, 000 \\
\hline$\leftarrow$ EXT & 739 & 0,060 & 12,415 &, 000 \\
\hline $\mathrm{SES}_{4} \leftarrow$ EXT & & & 9,484 & 0,000 \\
\hline$\leftarrow$ PER & 842 & 0,032 & 26,617 & 0,000 \\
\hline$\leftarrow$ PER & 859 & 0,040 & 21,628 & 0,000 \\
\hline $\mathrm{PER}_{3} \leftarrow$ PER & 664 & 0,099 & 6,694 & 0,000 \\
\hline $\mathrm{AVO}_{1} \leftarrow \mathrm{AVO}$ & 0,768 & 0,059 & 13,023 & $\overline{0,000}$ \\
\hline $\mathrm{AVO}_{2} \leftarrow \mathrm{AVO}$ & 0,632 & 0,071 & 8,900 & $\overline{0,000}$ \\
\hline $\mathrm{AVO}_{3} \leftarrow \mathrm{AVO}$ & 0,736 & 0,060 & 12,284 & 0,000 \\
\hline $\mathrm{AVO}_{4} \leftarrow \mathrm{AVO}$ & 0,773 & 0,060 & 12,984 & 0,000 \\
\hline $\mathrm{AVO}_{5} \leftarrow \mathrm{AVO}$ & 0,438 & 0,091 & 4,790 & 0,000 \\
\hline $\mathrm{AVO}_{6} \leftarrow \mathrm{AVO}$ & 0,685 & 0,057 & 12,100 & 0,000 \\
\hline $\mathrm{AVO}_{7} \leftarrow \mathrm{AVO}$ & 0,722 & 0,070 & 10,309 & 0,000 \\
\hline $\mathrm{AVO}_{8} \leftarrow \mathrm{AVO}$ & 0,705 & 0,060 & 11,818 & 0,000 \\
\hline $\mathrm{AVO}_{9} \leftarrow \mathrm{AVO}$ & 0,731 & 0,060 & 12,165 & 0,000 \\
\hline
\end{tabular}

Tabel 3. Hasil Analisis Model Pengukuran

Sumber: Hasil Analisis Data, 2020

Tabel 4 memperlihatkan AVE dan CR dari keenam variabel laten dengan indikator lengkap dan indikator yang dieliminasi.

Tabel 4. Kualitas Variabel Laten pada Model

\begin{tabular}{lccc|ccc}
\hline \multirow{2}{*}{ Variabel Laten } & \multicolumn{3}{c|}{ Item Lengkap } & \multicolumn{3}{c}{ Item Dieliminasi } \\
\cline { 2 - 7 } & Item & AVE & CR & Item & AVE & CR \\
\hline Motivasi Internal & 2 & 0,836 & 0,911 & 2 & 0,837 & 0,911 \\
\hline Sosial Ekonomi & 4 & 0,578 & 0,846 & 4 & 0,576 & 0,844 \\
\hline $\begin{array}{l}\text { Dukungan } \\
\text { Keluarga }\end{array}$ & 3 & 0,600 & 0,818 & 3 & 0,601 & 0,818 \\
\hline Motivasi Eksternal & 7 & 0,489 & 0,869 & 6 & 0,523 & 0,828 \\
\hline Persepsi Bertani & 3 & 0,629 & 0,834 & 3 & 0,629 & 0,834 \\
\hline Keberlanjutan & 9 & 0,483 & 0,892 & 8 & 0,524 & 0,897 \\
\hline
\end{tabular}

Sumber: Hasil Analisis Data, 2020

Mencermati dengan dieliminasinya SES $_{\mathbf{1}}$ dan $\mathbf{A V O}_{5}$ sebagai indikator reflektif dari latenlaten motivasi eksternal dan keberlanjutan usaha tani keluarga mampu meningkatkan nilai AVE melebihi 0,50, kausalitas antarlaten telah layak dianalisis pada submodel strukturalnya. 


\subsubsection{Analisis Model Struktural}

Pada Gambar 2 kausalitas antara laten eksogen dengan laten endogen terbedakan menjadi dua jenis, pengaruh langsung dan pengaruh tak langsung. Signifikansi pengaruhpengaruh langsung diperiksa melalui hipotesis H1 sampai H5 dan dua pengaruh tak langsung diperiksa melalui H6 dan H7. Pemeriksaan dilakukan dengan melakukan boot-strapping yang dijalankan pada 5.000 subsampel dan jenis uji yang digunakan uji dua arah (two-tail test). Hasil analisis model struktural ditunjukkan pada Tabel 5.

Memerhatikan Tabel 5, motivasi internal generasi muda Kabupaten Jembrana tidak terbukti berpengaruh pada persepsi generasi muda tentang usaha pertanian $\left(\mathrm{H}_{1}\right.$ ditolak). Sebaliknya, persepsi tentang usaha pertanian terbukti sangat dipengaruhi oleh motivasi eksternal generasi muda $\left(\mathrm{H}_{2}\right.$ diterima). Sebagai laten endogen, keberlanjutan pertanian di Kabupaten Jembrana terbukti dipengaruhi oleh motivasi eksternal dan persepsi generasi muda, dan secara substansial juga oleh motivasi internal generasi muda $\left(\mathrm{H}_{3}\right.$ diterima pada $\alpha=10 \%$ ).

Tabel 5. Kualitas Variabel Laten pada Model

\begin{tabular}{|c|c|c|c|c|}
\hline Kausalitas & Koefisien & $\begin{array}{l}\text { Simp. } \\
\text { Baku }\end{array}$ & $t$-Hitung & Nilai $p$ \\
\hline \multicolumn{5}{|c|}{ Pengaruh Langsung } \\
\hline INT $\rightarrow$ PER & 0,040 & 0,156 & 0,255 & $0,798^{\mathrm{n}}$ \\
\hline EXT $\rightarrow$ PER & 0,724 & 0,119 & 6,090 & 0,000 \\
\hline $\mathrm{INT} \rightarrow \mathrm{AVO}$ & 0,119 & 0,070 & 1,712 & 0,087 \\
\hline $\mathrm{EXT} \rightarrow \mathrm{AVO}$ & 0,563 & 0,108 & 5,200 & 0,000 \\
\hline $\mathrm{PER} \rightarrow \mathrm{AVO}$ & 0,230 & 0,101 & 2,288 & 0,022 \\
\hline \multicolumn{5}{|c|}{ Pengaruh Tak Langsung } \\
\hline $\mathrm{INT} \rightarrow \mathrm{AVO}$ & 0,009 & 0,041 & 0,225 & $0,822^{\mathrm{n}}$ \\
\hline $\mathrm{EXT} \rightarrow \mathrm{AVO}$ & 0,167 & 0,073 & 2,276 & 0,023 \\
\hline \multicolumn{5}{|l|}{ Pengaruh Total } \\
\hline INT $\rightarrow$ PER & 0,040 & 0,156 & 0,255 & 0,798 \\
\hline EXT $\rightarrow$ PER & 0,724 & 0,119 & 6,090 & 0,000 \\
\hline $\mathrm{INT} \rightarrow \mathrm{AVO}$ & 0,110 & 0,079 & 1,399 & $0,162^{\mathrm{n}}$ \\
\hline $\mathrm{EXT} \rightarrow \mathrm{AVO}$ & 0,730 & 0,076 & 9,572 & 0,000 \\
\hline $\mathrm{PER} \rightarrow \mathrm{AVO}$ & 0,230 & 0,101 & 2,288 & 0,022 \\
\hline
\end{tabular}

Keterangan:

ns Tidak signifikan

! Signifikan pada taraf uji $10 \%$

* Signifikan pada taraf uji 5\%

** $\quad$ Signifikan pada taraf uji $1 \%$

Sumber: Hasil Analisis Data, 2020
Pada kausalitas tidak langsung dan total, tidak terbukti peran mediasi dari persepsi generasi muda di kabupaten ini pada keberlanjutan usaha pertanian keluarga bersifat nyata $\left(\mathrm{H}_{6}\right.$ ditolak). Sebaliknya, persepsi generasi muda justru mampu memperkuat pengaruh dari motivasi eksternal pada keberlanjutan usaha $\left(\mathrm{H}_{7}\right.$ diterima). Fakta empiris ini dipertegas dengan memerhatikan koefisien jalur pada pengaruh total EXT $\rightarrow$ AVO yang meningkat menjadi 0,730 dari pengaruh langsung EXT $\rightarrow$ AVO sebesar 0,563.

Selain memeriksa koefisien-koefisien jalur pada model, seperti anjuran Hair et al. (2017), koefisien determinasi $\left(\mathrm{R}^{2}\right)$ dari dua laten endogen pada model (PER dan AVO) serta FAM dan SES sebagai dua laten orde satu dari EXT perlu diperiksa, dengan hasil diperlihatkan pada Tabel 6.

Tabel 6. Koefisien Determinasi $\left(\mathrm{R}^{2}\right)$ Laten Endogen

\begin{tabular}{lcl}
\hline Laten Endogen & Nilai $\mathrm{R}^{2}$ & Keterangan \\
\hline Persepsi sebagai Petani & 0,485 & Moderat \\
\hline $\begin{array}{l}\text { Keberlanjutan Usaha } \\
\text { Pertanian }\end{array}$ & 0,686 & Substansial \\
\hline Dukungan dari Keluarga & 0,840 & Substansial \\
\hline $\begin{array}{l}\text { Status Sosial Ekonomi } \\
\text { Keluarga }\end{array}$ & 0,809 & Substansial \\
\hline
\end{tabular}

Sumber: Hasil Analisis Data, 2020

Menurut Chin pada Kencana \& Mertha (2014), kemampuan laten eksogen dalam menjelaskan laten endogen diamati melalui nilai $\mathrm{R}^{2}$. Laten endogen terjelaskan secara substansial jika $R^{2} \geq 0,67$; terjelaskan moderat bila $0,33 \leq \mathrm{R}^{2}<0,67$; dan terjelaskan lemah bila $0,19 \leq \mathrm{R}^{2}<0,33$. Mencermati Tabel 6 dan kriteria Chin, selain persepsi sebagai petani yang terjelaskan moderat, ketiga laten endogen lainnya terjelaskan substansial oleh laten-laten eksogen.

'Kekuatan' dari setiap laten eksogen dalam menjelaskan secara langsung laten endogen yang bersesuaian bisa dicermati dengan memeriksa statistik Cohen $f^{2}$ (Henseler et al., 2009 , p. 304). Statistik $f^{2}$ yang dihitung menggunakan persamaan

$$
f^{2}=\frac{\mathrm{R}_{\text {included }}^{2}-\mathrm{R}_{\text {excluded }}^{2}}{1-\mathrm{R}_{\text {included }}^{2}}
$$

dengan $\mathrm{R}_{\text {included }}^{2}$ dan $\mathrm{R}_{\text {excluded }}^{2}$ masing-masing menyatakan nilai $R^{2}$ saat laten eksogen disertakan dan tidak disertakan pada model. 
Menggunakan statistik $f^{2}$, kemampuan penjelas laten eksogen dikatakan lemah bila $0,02 \leq$ $f^{2}<0,15$; dikatakan medium bila $0,15 \leq$ $f^{2}<0,35$; dan disebut kuat bila $f^{2} \geq 0,35$. Nilai $f^{2}$ dirinci pada Tabel 7 .

Tabel 7. Matriks Nilai $f^{2}$

\begin{tabular}{lcccc}
\hline Laten & \multicolumn{4}{c}{ Laten Endogen } \\
\cline { 2 - 5 } Eksogen & AVO EXT FAM & INT & PER & SES \\
\hline Motif & INT & 0,022 & & 0,002 \\
Internal & & 5,258 & 0,504 & 4,236 \\
\hline $\begin{array}{l}\text { Motif } \\
\text { Eksternal }\end{array}$ & EXT & 0,332 & & \\
\hline Persepsi & PER & 0,087 & & \\
\hline
\end{tabular}

Sumber: Hasil Analisis Data, 2020

\subsection{Diskusi}

Model persamaan struktural yang digunakan untuk mengetahui determinan keengganan generasi penerus melanjutkan usaha tani keluarga yang berdampak pada keberlanjutannya di Kabupaten Jembrana membuktikan motivasi eksternal dan persepsi generasi muda meneruskan usaha tani keluarga dan bekerja di sektor pertanian menunjukkan pengaruh nyata dengan besar pengaruh yang berbeda-beda. Motivasi eksternal yang terefleksikan ke dalam laten dukungan dan laten kondisi sosial ekonomi keluarga memberikan pengaruh moderat kepada keberlanjutan usaha tani keluarga, sedangkan persepsi generasi muda tentang usaha pertanian hanya berpengaruh lemah.

Studi dengan tema sama dilakukan Berk (2018) di Turki menunjukkan salah satu variabel yang berpengaruh nyata pada 'keluarnya' petani muda dari usaha pertanian yang digelutinya tidak terlepas dari pendapatan per bulan yang secara relatif lebih kecil bila dibandingkan bekerja di sektor nonpertanian. Temuan yang sama juga teramati pada studi ini. Pendapatan dari usaha tani yang tidak mencukupi kebutuhan rumah tangga $\left(\mathrm{SES}_{2}\right)$ sebagai salah satu indikator reflektif dari motivasi eksternal generasi muda enggan melanjutkan usaha tani keluarga dengan nilai loading tertinggi serta dukungan orang tua untuk bekerja di sektor yang diinginkan $\left(\mathrm{FAM}_{3}\right)$ merupakan dua penyebab utama dari kuatnya pengaruh motivasi eksternal generasi muda tidak melanjutkan usaha tani keluarga.

Studi literatur tentang penuaan petani dan berkurangnya tenaga kerja muda di sektor pertanian di Indonesia yang dilakukan Susilowati (2016) menyebutkan, generasi muda cenderung mencari pekerjaan di sektor nonpertanian mengingat sektor pertanian kurang dapat memenuhi kebutuhan hidup. Riset ini juga mengkonfirmasi hal serupa. Keengganan generasi muda di Kabupaten Jembrana untuk melanjutkan usaha tani keluarga juga terefleksi pada keyakinan generasi muda bahwa secara ekonomi pekerjaan di sektor nonpertanian lebih menjanjikan dan pendapatan yang diperoleh lebih pasti bila dibandingkan produk pertanian yang tergantung kepada musim.

Hal ketiga yang juga terjustifikasi pada studi ini adalah persentase penduduk yang berpendidikan SMA ke atas dengan kompetensi bukan di bidang pertanian. Meningkatnya jenjang pendidikan generasi muda yang kompetensinya bukan di bidang pertanian merupakan salah satu ancaman bagi keberlanjutan usaha tani di Kabupaten Jembrana. Lokasi rumah yang terletak relatif jauh dari lahan milik juga menjadi penyebab semakin tidak tertariknya generasi muda meneruskan usaha keluarga. Faktor kedekatan lahan dengan rumah tinggal yang menjadi determinan keberlanjutan usaha tani juga sejalan dengan temuan riset Berk (2018).

\section{SIMPULAN DAN SARAN}

\subsection{SIMPULAN}

Berkurangnya tenaga kerja muda di sektor pertanian merupakan fenomena yang teramati di berbagai belahan dunia termasuk di Indonesia. Riset ini, yang ditujukan untuk mengetahui determinan keengganan generasi muda serta kausalitasnya dengan keberlanjutan usaha tani di Kabupaten Jembrana, secara umum menemukan generasi muda cenderung tidak berminat untuk meneruskan usaha tani keluarga. Secara khusus, riset ini menyimpulkan:

1. Keahlian dan pengalaman generasi muda yang kurang mendukung bekerja di sektor pertanian sebagai refleksi motivasi internal ternyata tidak berpengaruh terhadap keengganan generasi muda bekerja di sektor ini. Generasi muda hanya beranggapan bertani melelahkan dan lebih cocok dilakukan orangtua;

2. Motivasi eksternal sebaliknya terbukti nyata memengaruhi keengganan generasi muda melanjutkan usaha tani keluarga yang akan 
berdampak pada keberlanjutan pertanian di Kabupaten Jembrana. Pendapatan kegiatan bertani yang lebih rendah bila dibandingkan bekerja di sektor non-pertanian merupakan faktor penarik (pull factor) generasi muda untuk bekerja di sektor non-pertanian;

3. Jenjang pendidikan yang lebih tinggi bila dibandingkan pendidikan orang tuanya serta kompetensi di luar bidang pertanian, juga merupakan faktor penarik lain bagi generasi muda di Kabupaten Jembrana bekerja di sektor nonpertanian.

\subsection{Saran}

Terkait dengan temuan riset ini sejumlah rekomendasi diajukan, sebagai berikut:

1. Meningkatkan kepercayaan generasi muda bahwa bekerja di sektor pertanian tidak kalah menguntungkan bila bekerja di sektor non-pertanian;

2. Terkait dengan nilai jual produk pertanian, Pemerintah Kabupaten Jembrana c.q. Perusahaan Daerah (PERUSDA) disarankan untuk merintis, meningkatkan, dan membina kerja sama dengan industri pariwisata yang berkembang pesat di daerah ini untuk menerima dan menggunakan produk pertanian daerah sekaligus memberikan pelatihan peningkatan mutu produk, bekerja sama dengan lembaga pendidikan tinggi di bidang pertanian;

3. Menyarankan Badan Usaha Milik Desa (BUM Desa) memperbesar pinjaman modal untuk aktivitas pertanian. BUM Desa juga disarankan semakin mengintensifkan kerjasama dengan petani dalam menampung produk pertanian sebelum diserahkan pemasarannya kepada PERUSDA.

\section{DAFTAR PUSTAKA}

Berk, A. (2018). Factors a ecting the exit from farming of young farmers in Turkey: the case of Nigde province. Ciencia Rural, 48(8), 1-8.

Bollen, K. A. (2002). Latent Variables in Psychology and the Social Sciences. Annual Review of Psychological, 53, 605-634.
BPS Indonesia (2020). Statistik Indonesia 2020.Jakarta, ID: BPS Indonesia. ISSN: 0126-2912

BPS Kabupaten Jembrana (2020). Kabupaten Jembrana dalam Angka 2020. Denpasar, ID: BPS Kabupaten Jembrana. ISSN: 02155540 .

BPS Provinsi Bali (2020). Provinsi Bali dalam Angka 2020. Denpasar, ID: BPS Provinsi Bali. ISBN: 978-602-1393-68-0.

Churchill G A, J. (1979). A Paradigm for Developing Better Measures of Marketing Constructs. Journal of Marketing Research, $16(1), 64-73$.

Henseler, J., Ringle, C. M., \& Sinkovics, R. R. (2009). The Use of Partial Least Squares Path Modeling in International Marketing. In S. T. Cavusgil, R. R. Sinkovics, \& P. N. Ghauri (Eds.), Advances in International Marketing (pp. 277-319). UK: Emerald.

Hair, J. F., Black, W. C., Babin, B. J., \& Anderson,

R. E. (2019). Multivariate Data Analysis (8th ed.). Hampshire, UK: Cengage Learning, EMEA.

Hair, J. F., Hult, G. T. M., Ringle, C. M., \& Sarstedt,

M. (2017). A Primer on Partial Least Squares Structural Equation Modeling (PLS-SEM) (2nd ed.). USA: SAGE Publications, Inc.

Kementerian PPPA (2018). Statistik Gender Tematik: Pro l Generasi Milenial Indonesia. Jakarta, ID: Kementerian Pemberdayaan Perempuan dan Perlindungan Anak.

Kencana, E. N. \& Mertha, I. W. (2014). People Participation as Social Capital Form for Realizing Sustainable Ecotourism. International Journal of Social, Management, Economics and Business Engineering, 8(10), 3014-3020.

Ringle, C. M., Wende, S., \& Becker, J.-M. (2015). Smartpls 3. http://www.smartpls.com. Last accessed on 12 October 2020.

Ryan, R. M. \& Deci, E. L. (2000a). Intrinsic and Extrinsic Motivations: Classic Definitions and New Directions. Contemporary Educational Psychology, 25, 54-67. 
Ryan, R. M. \& Deci, E. L. (2000b). SelfDetermination Theory and the Facilitation of Intrinsic Motivation, Social Development, and Well-Being. American Psychologist, 55(1), 68-78.

Susilowati, S. H. (2016). Fenomena Penuaan Petani dan Berkurangnya Tenaga Kerja Muda Serta Implikasinya Bagi Kebijakan Pembangunan Pertanian. Forum Penelitian Agro Ekonomi, 34(1), 35-55.

Wetzels, M., Odekerken-Schrder, G., \& van Oppen, C. (2016). Using PLS Path Modeling for Assessing Hierarchical Constructs Models: Guidelines and Empirical Illustration. MIS Quarterly, 33(1), 177-195. 